\title{
Static and Dynamic Characteristics of a Double Armature DC Linear Motor
}

\author{
A. Basak*, A. F. Flores-Filho**, Y. Kano (member)*** and M. Yamaguchi (member) ${ }^{* * *}$ \\ * School of Engineering, Cardiff University, UK, ${ }^{* *}$ Federal University of Rio Grande de Sul, Brazil and \\ *** Tokyo University of Agriculture and Technology, 184, Tokyo, Japan.
}

\section{Abstract}

\begin{abstract}
A brushless and slotless dc linear motor employing a movable set of neodymium-boron-iron type magnets is discussed in this paper. The motor can be used as a linear stepping motor as well, due to its unique topology. The flux density at specific points and the static force along the travel length of the motor were measured. $A$ 3D finite element analysis of the flux distribution and of the static force were carried out. The dynamic characteristics such as velocity, output power and efficiency for various conditions were measured.
\end{abstract}

Keywords: linear motor, dc motor, permanent magnet, static force, dynamic characteristic

\section{Introduction}

There are advantages in some applications when using direct linear drives instead of converting rotary motion into linear movement. The linear motor can be more reliable and compact, presents better dynamic response, and requires less maintenance when replacing drives based on rotary motors and other linear actuators, e.g. pneumatic and hydraulic ones ${ }^{1-5}$. This paper describes the development of a large novel voice coil linear dc motor featuring a double square armature. Permanent magnets with maximum energy product of large value act as field sources and surround three sides of each armature, thus producing considerably large force-to-mass ratios. This motor is classified as a short secondary type, and may be used as a slotless linear stepping motor.

An increment in the maximum permeability of the mild steel, the linear motor is made from, was achieved by annealing. It resulted in a 5\% increase of the developed force. An analytical process was developed to find an optimum shape for the slider back iron. The main constraint in this optimisation process was the saturation induction of the material the back iron is made of. A finite element analysis produced results that validated the analytical optimisation process.

In order to improve the understanding of the linear motor and validate its theoretical and numerical results, a comprehensive series of tests was carried out. These tests were conceived to measure various parameters under different operating conditions. The linear motor was driven by an electronic system which controlled each coil section of the two armature windings to provide conditions for dynamic tests.

\section{Principles of operation}

The double armature homopolar brushless dc linear motor was conceived with the main idea of making a linear motor with improved sensitivity ${ }^{6}$. The approach chosen was to surround the sides of the armature with high maximum energy product permanent magnets. This resulted in an enlarged active length of the armature conductors. The linear motor had to be provided with a closed magnetic circuit for the magnetic flux supplied by the permanent magnets. In this case the solution was found by using a second armature to complete the magnetic circuit. The external side of each armature was not encircled by any permanent magnets, thus the terminals of the coil sections could be easily accessible for connection to the power supply as shown in Fig. 1. The slotless rectangular shaped armature core made of two long and two short bars of heattreated mild steel uses a double armature configuration. Gaps have been made by nonmagnetic material along the armature magnetic circuit. They avoid magnetic saturation and minimise the magnetic pull end-effect. Furthermore, a better motor time constant can be achieved with them. The topology of this motor is quite different from those presented by Honds and Meyer? The armature winding is distributed along the long bars. On each bar, there are fourteen independent six-layer 159-turn coil sections

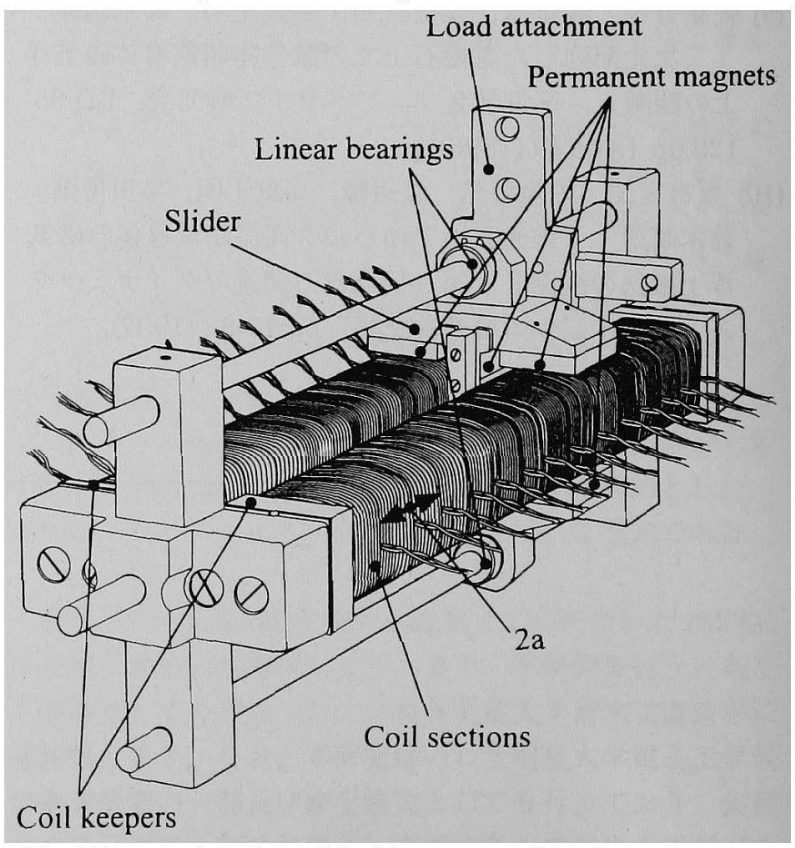

Fig. 1 Perspective view of double armature homopolar brushless d.c. linear motor 
wound with $0.5 \mathrm{~mm}$ diameter copper wire with polyurethene insulation. Each coil section is $15.3 \mathrm{~mm}$ in length and fed with switched currents. There is physical displacement of the coils of one bar with respect to the ones on the other. If the length of each section is $2 a$ in $z$ direction, the distance between two consecutive coils, one on the first bar and the other on the second one, is $a$, which is the displacement step of the slider as well. The slider moves along the travel length supported by a pair of linear bearings and two parallel shafts. Hanaoka et $\mathrm{al}^{8}$ used Vwheels instead of linear bearings in their motor.

The cross-section of the slider and the armature are shown in Fig. 2. The five permanent magnet blocks are arranged in such a way around the armature bars $a$ and $b$ that the excitation flux converges to bar $a$ through three lateral sides from the magnet blocks placed opposite to the air gaps. The magnetic path of each permanent magnet closes through the slider back iron and the armature bars. The model of the linear motor presents symmetries with respect to $z y$ and $z x$ planes. On the other side, the excitation magnetic flux diverges from bar $b$ towards the permanent magnet pieces placed opposite to the air gaps.

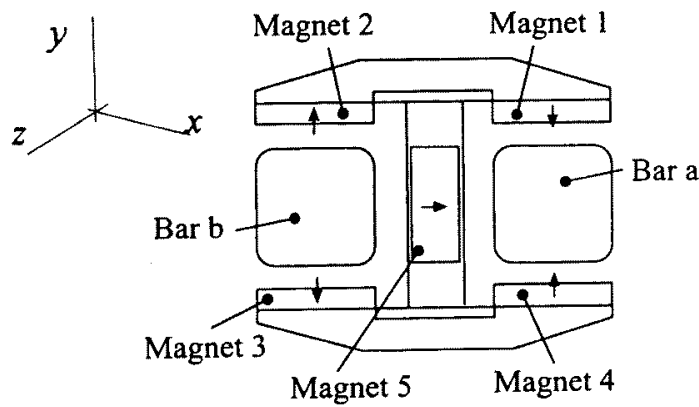

\section{$\longleftarrow$ Direction of $\Phi$ through the permanent magnets}

Fig. 2 Frontal view of the slider

\subsection{Force, Sensitivity and Power}

The assessment of the longitudinal force initially disregards the existence of any reluctance force and leakage flux. The equation given below is derived from the Lorentz's law and is employed to obtain a scalar expression for the force the linear motor can develop.

$$
\bar{F}=\int_{V} \bar{B} \times \bar{J} d V
$$

where $V$ is the volume of the part of the armature winding that effectively produces the force on the slider, in other words, it comprehends the conductors on one armature bar that are subjected to the air gap flux density $\bar{B}$. As $\bar{B}$ is perpendicular to the current density, $\bar{J} \mathrm{Eq}$ (1) assumes a scalar form

$$
F=\int_{V} B J d V
$$

The volume of the active armature coils is considered with the aid of Fig. 3 . If the fringing flux is not taken into account,

$$
V=3 \omega_{c} \omega_{m} l_{c}
$$

where $l_{c}$ is the active length of the conductor on either side of the armature bar, $\omega_{c}$ is the width of the coil section (m) and $\omega_{\mathrm{m}}$ is the width of the magnet $(\mathrm{m})$. The equation (2) can be modified to

$$
F=3 \omega_{c} \omega_{m} l_{c} J B
$$

where $\omega_{c} \omega_{m} J=N I$

which is the m.m.f. of the active part of the armature winding. $N$ is the number of turns of this active part. The force is, therefore,

$$
\begin{array}{ll}
F=3 N B I l_{c} \\
\text { or } \quad F=\frac{3 N \phi I}{\omega_{m}} \\
\text { or } \quad F=3 n \phi I
\end{array}
$$

where $n$ is number of conductors per metre of armature length and $\phi$ is magnetic flux.

The sensitivity is

$$
S_{f}=\frac{F}{I}=3 n \phi
$$

The constant ' 3 ' in Eq. 8 corresponds to the number of permanent magnet pieces surrounding each armature bar.

The electromagnetic power is given by

$$
P_{e}=E_{a} I=F v=3 n \phi I v
$$

and the e.m.f. of the coils is

$$
\begin{aligned}
& E_{a}=3 n \phi v=S_{f} v \\
& =V_{t}-I r_{c}-L_{c} \frac{d i}{d t}
\end{aligned}
$$

where $V_{t}$ is the terminal voltage, $r_{c}$ and $L_{c}$ are the resistance and inductance of the coil. 


\subsection{Design and Construction}

The design was mainly carried out with the knowledge of leakage coefficient, fringing coefficient, magnet length, air gap length, air gap area, reluctance of various magnetic

(a) Lateral view

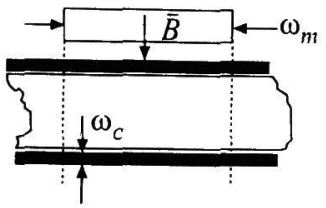

b) Frontal view

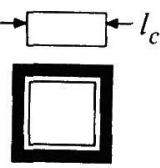

Fig. 3 Section of the armature bar with one permanent magnet

paths. In order to obtain the optimum values of developed force the expression Eq. 7 is made to converge. The operating point of the permanent magnets CRUMAX 315 was initially set at $B_{m}=0.59 T$ and $H_{m}=-448 \mathrm{kA} / \mathrm{m}$ which coincides with their maximum energy product ${ }^{9-10}$ The operating point was assumed to be the same for all

Table I Measured and numerical values of the air gap flux density

\begin{tabular}{|c|c|c|c|c|c|c|c|c|c|}
\cline { 2 - 9 } \multicolumn{1}{c|}{} & \multicolumn{6}{c|}{$\begin{array}{c}\text { Airgaps flux density in the middle of the } \\
\text { permanent magnet face (mT) }\end{array}$} \\
\hline Slider & \multicolumn{3}{|c|}{$\mathrm{B}_{\mathrm{g} 1}$} & \multicolumn{3}{c|}{$\mathrm{B}_{\mathrm{g} 2}$} & \multicolumn{3}{c|}{$\mathrm{B}_{\mathrm{g} 3}$} \\
\cline { 2 - 10 } position(mm) & FEM & Meas & diff\% & FEM & Meas & diff\% & FEM & Meas & diffo\% \\
\hline-91.8 & 561 & 518 & 7.6 & 564 & 522 & 7.5 & 564 & 523 & 7.3 \\
\hline-61.2 & 551 & 512 & 7 & 552 & 518 & 6.2 & 552 & 518 & 6.2 \\
\hline-30.6 & 551 & 514 & 6.8 & 552 & 518 & 6.2 & 552 & 517 & 6.3 \\
\hline 0.0 & 551 & 512 & 7 & 552 & 518 & 6.1 & 552 & 517 & 6.3 \\
\hline 30.6 & 551 & 512 & 7 & 552 & 518 & 6.1 & 552 & 517 & 6.4 \\
\hline 61.2 & 550 & 512 & 7 & 551 & 518 & 6 & 551 & 516 & 6.4 \\
\hline 91.8 & 545 & 511 & 6.2 & 548 & 517 & 5.6 & 548 & 516 & 5.9 \\
\hline
\end{tabular}

\begin{tabular}{|c|c|c|c|c|c|c|c|c|c|}
\hline \multirow{3}{*}{$\begin{array}{c}\text { Slider } \\
\text { position(mm) }\end{array}$} & \multicolumn{9}{|c|}{$\begin{array}{l}\text { Airgaps flux density in the middle of the } \\
\text { permanent magnet face (mT) }\end{array}$} \\
\hline & \multicolumn{3}{|c|}{$\mathrm{B}_{\mathrm{g} 4}$} & \multicolumn{3}{|c|}{$\mathrm{B}_{\mathrm{g} 5 \mathrm{a}}$} & \multicolumn{3}{|c|}{$B_{g} 5 b$} \\
\hline & FEM & Meas & diff $\%$ & FEM & Meas & diff $\%$ & FEM & Meas & diff\% \\
\hline-91.8 & 561 & 521 & 7.2 & 571 & 537 & 6 & 571 & 564 & 1.3 \\
\hline-61.2 & 551 & 515 & 6.5 & 562 & 540 & 3.9 & 562 & 556 & 1.1 \\
\hline-30.6 & 551 & 516 & 6.3 & 563 & 540 & 4 & 563 & 558 & 0.8 \\
\hline 0.0 & 551 & 517 & 6.1 & 563 & 541 & 3.9 & 563 & 559 & 0.7 \\
\hline 30.6 & 551 & 516 & 6.3 & 563 & 540 & 4.1 & 563 & 556 & 1.3 \\
\hline 61.2 & 550 & 515 & 6.4 & 561 & 539 & 4 & 561 & 558 & 0.5 \\
\hline 91.8 & 545 & 515 & 5.5 & 518 & 512 & 1.1 & 518 & 508 & 1.9 \\
\hline
\end{tabular}

permanent magnets. The nominal armature current was chosen to be $1.5 \mathrm{~A}$.

The final design produced a force of $14 \mathrm{~N}$, which corresponds to a sensitivity of 9.3N/AT. The travel length of the linear motor was initially chosen to be $214.2 \mathrm{~mm}$. Owing to the need to accomodate the slider and fourteen coil sections on each armature bar, it was practically reduced to $184 \mathrm{~mm}$ (difference between armature bar length and slider length is 214.2-27.6 $=186.6 \mathrm{~mm}$ ). Coil sections made from enamelled copper wire of $0.5 \mathrm{~mm}$ diameter having resistance of $1.52 \mathrm{ohm}$ at $25{ }^{\circ} \mathrm{C}$ had length, thickness and nominal active length of $15.3 \mathrm{~mm}, 3.5 \mathrm{~mm}$ and $24 \mathrm{~mm}$ respectively. The number of turns and number of layers of each coil section was 159 and 6 respectively.

One of the advantages of using an armature with coil sections, is to have smaller inductance and time constant than in the case of an armature with continuous large windings.

The dimensions of the permanent magnet pieces depend on their second quadrant characteristic, the desired airgap flux density, the dimensions of the coil sections and the air gap. The thickness of the permanent magnets is same as the length of the respective air gaps.

The permanent magnets are placed in the inner part of the slider back iron. Magnets 1 to 4 are glued to their position to avoid being dislocated by the electromagnetic force. Magnet 5 is kept enclosed in a brass piece that also holds the two halves of the slider together.

The width of the permanent magnet pieces has been chosen to cover the length of two coil sections. The total length of two coil sections $(30.6 \mathrm{~mm})$ is marginally larger than the width of the permanent magnets. This was done on purpose to make a better use of the fringing flux from the permanent magnets without enlarging the coil sections too much.

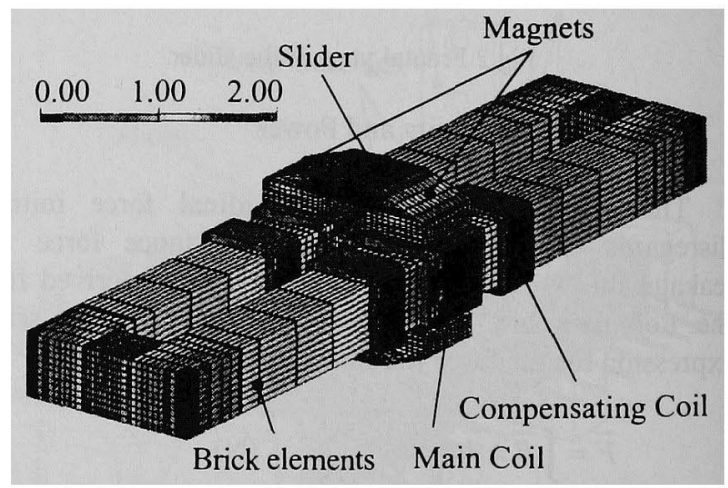

Fig.4 Distribution of flux density (in tesla) in the linear motor

\section{Results and discussion}

The linear motor was tested under different conditions. Numerical results produced by the FEM are presented and 
compared with the experimental ones wherever possible. A good correlation between them was obtained.

\subsection{Static tests}

The static tests and simulations were focused on the flux distribution throughout the volume of the prototype and the effect of the current, when it is present, on the flux

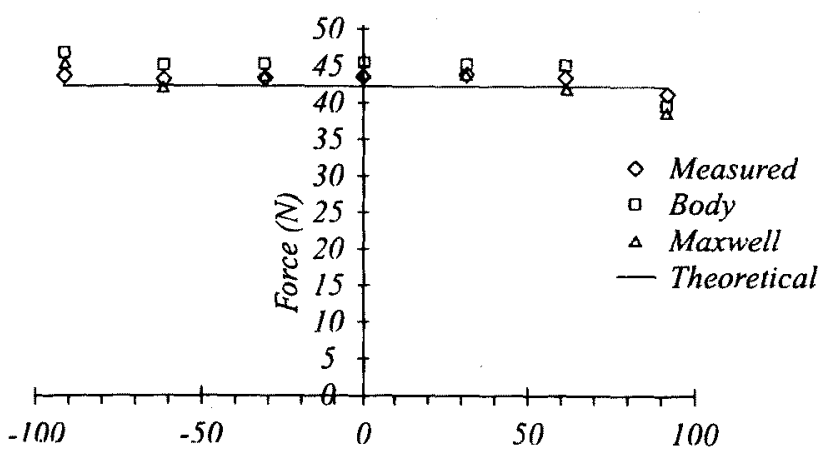

Fig.5 The static force versus position

Table II. Various ratios obtained by measurement and numerical methods.

\begin{tabular}{|l|c|c|c|c|}
\cline { 2 - 5 } \multicolumn{1}{c|}{} & Measured & Body & Maxwell & Theoretical \\
\hline$S_{f}(\mathrm{~N} / \mathrm{AT})$ & 9.54 & 9.98 & 9.71 & 9.33 \\
\hline$\varphi\left(\mathrm{N} / \mathrm{cm}^{3}\right)$ & 0.965 & 1.010 & 0.982 & 0.944 \\
\hline$\left.\gamma_{\left(\mathrm{N} / \mathrm{kg} \text { or } \mathrm{m} / \mathrm{s}^{2}\right)}\right)$ & 120.74 & 126.39 & 122.95 & 118.14 \\
\hline$\gamma_{c}(\mathrm{~N} / \mathrm{kgA})$ & 0.084 & 0.088 & 0.086 & 0.083 \\
\hline
\end{tabular}

Table III. Definition and description of the cases analysed.

\begin{tabular}{|c|l|}
\hline Case Number & \multicolumn{1}{|c|}{ Description } \\
\hline 1 & Armature current $I=0$ \\
\hline 2 & Armature curnent $I=1.5 \mathrm{~A}$, no compensation of armature flux \\
\hline 3 & Armature current $I=3 \mathrm{~A}$, no compensation of armature flux \\
\hline 4 & Armature current $I=4.5 \mathrm{~A}$, no compensation of armature flux \\
\hline 5 & Aramture current $I=1.5 \mathrm{~A}$, with compensation of armature flux \\
\hline 6 & Armature current $I=3 \mathrm{~A}$, with compensation of armature flux \\
\hline 7 & Armature current $I=4.5 \mathrm{~A}$, with compensation of armature flux \\
\hline 8 & $\begin{array}{l}\text { Double action configuration, armature current } I=1.5 \mathrm{~A} \text {, with } \\
\text { compensation of armature flux }\end{array}$ \\
\hline 9 & $\begin{array}{l}\text { Double action configuration, armature curnent } I=3 \mathrm{~A} \text {, with } \\
\text { compensation of armature flux }\end{array}$ \\
\hline 10 & $\begin{array}{l}\text { Double action configuration, armature curnent } I=4.5 \mathrm{~A} \text {. with } \\
\text { compensation of armature flux }\end{array}$ \\
\hline
\end{tabular}

distribution, saturation of the magnetic circuit and force. The results were obtained with the slider of the linear

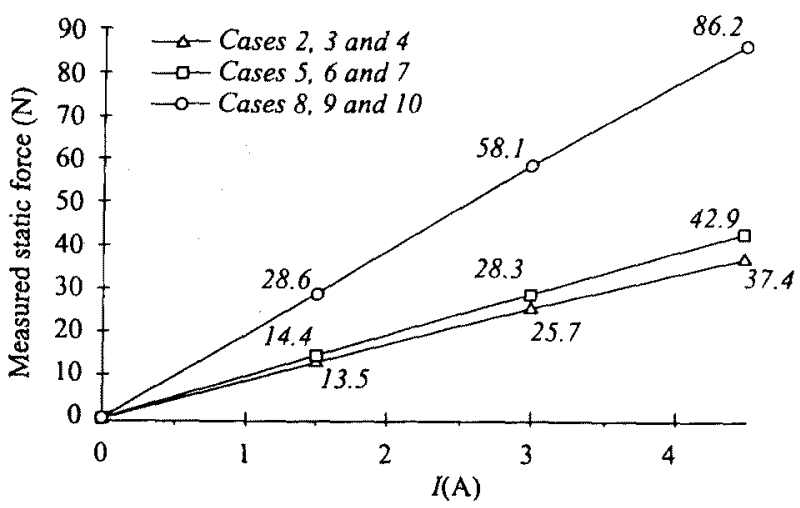

Fig.6 Performance of the linear motor in terms of static forces

Table IV. Sensitivity and force-to-mass ratios with slider at $z=0$.

\begin{tabular}{|c|c|c|c|c|c|c|c|c|}
\cline { 2 - 9 } \multicolumn{1}{c|}{} & \multicolumn{3}{c|}{ Sf(N/AT) } & \multicolumn{4}{c|}{$\gamma\left(\right.$ (N/kg or m/s $\left./{ }^{2}\right)$} \\
\hline Cases & Measured & Body & Maxwell & Theoretical & Measured & Bady & Maxwell & Theoretical \\
\hline 2 & 8.99 & 9.73 & 9.42 & 9.33 & 37.95 & 41.04 & 39.75 & 39.38 \\
\hline 3 & 8.57 & 9.37 & 8.95 & 9.33 & 72.29 & 79.04 & 75.53 & 78.76 \\
\hline 4 & 8.32 & 9.01 & 8.36 & 9.33 & 105.30 & 114.09 & 105.85 & 118.14 \\
\hline 5 & 9.58 & 9.99 & 9.87 & 9.33 & 40.43 & 42.17 & 41.63 & 39.38 \\
\hline 6 & 9.44 & 9.99 & 9.70 & 9.33 & 79.66 & 84.26 & 81.86 & 78.76 \\
\hline 7 & 9.54 & 9.98 & 9.71 & 9.33 & 120.74 & 126.39 & 122.95 & 118.14 \\
\hline 8 & 19.05 & 19.97 & 19.40 & 19.40 & 80.38 & 84.25 & 81.86 & 78.76 \\
\hline 9 & 19.38 & 19.97 & 19.40 & 19.40 & 163.50 & 168.52 & 163.71 & 157.52 \\
\hline 10 & 19.16 & 19.90 & 19.40 & 19.40 & 242.48 & 251.87 & 245.57 & 236.29 \\
\hline
\end{tabular}

Case 7

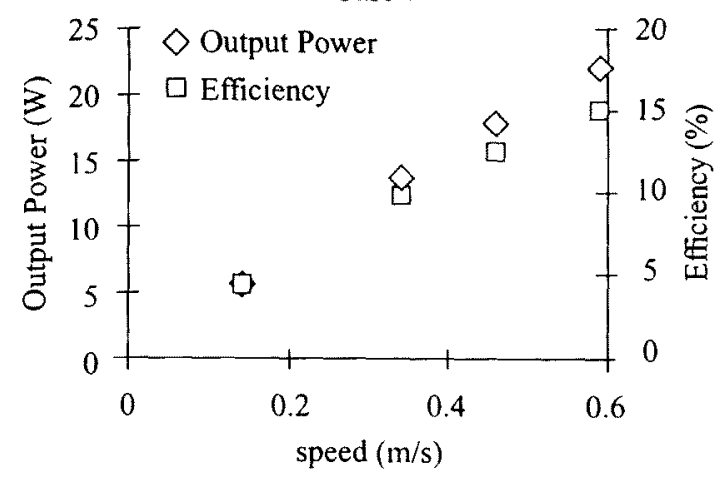

Fig. 7 Output power and efficiency of the linear motor 
motor placed at seven different positions along the travel length. The experimenal results and the predictions obtained by the FEM analysis are closely correlated.

The numerically obtained flux density distribution in the entire volume of linear motor is shown in Fig. 4. In this case the armature current is $4.5 \mathrm{~A}$ and the armature fringing flux is compensated by energising coils adjacent to the main coils situated opposite to the magnets. The slider is at the middle of the travel length.

Table 1 shows the measured and numerical values of the air gap flux density at a position by the centre of the permanent magnets and $0.5 \mathrm{~mm}$ away from them towards the armature bar.

The force was computed using two methods: the body force and Maxwell's stress tensor ${ }^{11}$. The static force curve is presented in Fig. 5 and the ratios are shown in Table 2. In terms of difference with respect to the measured value, the maximum found by body force method was $6.8 \%$ and $4 \%$ for Maxwell's stress tensor.

Table 3 gives the definitions and descriptions of the cases analysed. These cases cover most of the ways the linear motor can operate.

The performance of the linear motor in terms of static force under different situations represented by cases 2 to 10, Fig.6, can be analysed with the aid of the data, Table 4 .

\subsection{Dynamic tests}

In the dynamic tests, the output power and the efficiency of the linear motor have been evaluated. The test was carried out to estimate the performance of the linear motor in terms of output power and efficiency. For each case, a load was applied. The output power and efficiency of the motor for armature current $4.5 \mathrm{~A}$ and with compensation of armature flux are shown with variation of the speed in Fig. 7. A load of $3.5 \mathrm{kgf}$ was attached to the slider to obtain the characteristics.

\section{Conclusions}

The topology of the machine made possible a more efficient use of the armature coils and magnetic circuit. The linear motor proved to be able to produce a high sensitivity, measured values ranging from 9.3N/AT to 19N/AT were obtained; furthermore, its high force-to-mass ratio indicates that its acceleration at constant current can be large

A good correlation was obtained between the computed values of force using Maxwell's stress tensor method and the measured ones

In comparison to rotary d.c. motors, which can have efficiencies as high as $90 \%$, the d.c. linear motors in general are less efficient. This is a characteristic of this kind of machine, the airgap is large due to a slotless armature, and, as a result, the airgap flux density is low. However, efficiency is more important when the machine works in a continuous duty cycle. Depending on the duty cycle the linear motor is subjected to, the latter may perform better than its rotary counterpart.

(Manuscript received Oct. 13, '97, revised April 2, '98)

\section{References}

[1] A. Basak, "Permanent magnet d.c. linear motors", Oxford University Press, 1996.

[2] C. W. Green and R. J. A. Paul, "Application of d.c. linear machines as short-stroke and static actuators", Proc. EEE, Vol.116, No.4, 1969, pp 599-604.

[3] G. Ratcliff and J. Griffiths, Journal of Scientific Instruments, Vol.41, 1964, pp 267-8

[4] H. Wakiwaka, T. Ninomiya, T. Morimura and H. Yamada, "Analysis of magnetic field and dynamic responses of linear d.c. motor for pen recorder", Simulation and design of applied electromagnetic systems (ed. T. Honma), Elsevier Science, 1996, pp 573-6.

[5] J. Draeger and H. Moczala, "Elektrische linear-kleinmotoren" Actuator'88, Bremen, Germany, 9-10 June 1988, pp 202-227 (in German).

[6] UK Patent, "Linear Electric Motor", published 10.01.1996, No. GB 2274551

[7] L. Honds and K. H. Meyer, "A linear d.c. motor with permanent magnets", Philips Tech. Rev. Vol.40, No.11/12, 1982, pp 329-337

[8] M. Hanaoka, H. Miyaji, Y. Kano, S. Hasebe and K. Ohta, "Analysis of moving magnet d.c. linear motor with two straight stators", Electrical Engineering in Japan, Vol.112, No.5, 1992, pp 100-7.

[9] R. J. Parker, "Advances in permanent magnetism", John Wiley \& Sons, 1990

[10] P. Campbell, "Permanent magnet materials and their applications", Cambridge University Press, 1994.

[11] A. Basak, A. Matsumura, J. Kaczmarek and G. Lloyd, "Computation of flux and force in an $\mathrm{SmCos}_{5}$ dc linear motor with U-spring supports", Journal of Magnetism and Magnetic Materials, Vol.133, 1994, pp 583-586.

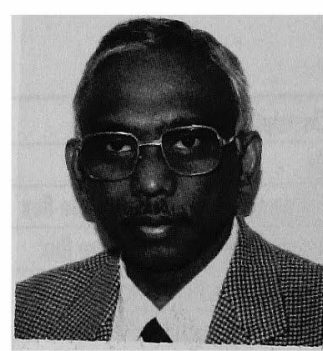

Amitava Basak was born in Calcutta, India. He received the B.E degree in electrical engineering from the University of Calcutta in 1966 and M.Sc. and Ph.D. degrees from the University of Wales, U.K., in 1971 and 1975, respectively. His $\mathrm{Ph}$.D. work dealt with the use of ferrite magnets in d.c. linear motors.

Dr. Basak is currently a lecturer in the School of Engineering, Cardiff University of Wales. He is the research group leader in the field of computation of localised magnetic flux and core loss in electrical steels and amorphous materiais when used in large electrical machines including transformers, high energy permanent magnets and their applications in d.c. linear motors.

Dr. Basak is the author of two books published by Cambridge University Press and Oxford University Press and co-editor of a book on Magnetics. He is a member of the Institute of Electrical Engineers in UK.

Aly Ferreira Flores Filho was born in Porto Alegre in Brazil in 1960. He is a lecturer in the Federal University of Rio Grande do 
Sul where he also graduated from. He obtained his Ph.D. degree from the University of Wales in 1996. The title of his Ph.D. thesis is 'Investigation of a double armature homopolar brushless d.c. linear motor'. He is the head of the electrical machines laboratory in his University and a member of the IEEE.

Yoshi Kano (Member) was born in 1938. He received a doctoral degree in Engineering from Meiji University in 1970. Since 1970, he has been with Tokyo University of Agriculture and Technology, where he is presently a professor in the Faculty of Engineering and the Graduate school of Bio-Applications \& Systems Engineering (BASE).

His research interests are mainly in the area of analysis, design of electromagnetic actuators, and the instrumentation on agriculture and biology.

$\mathrm{He}$ is a member of the Institute of Electrical Engineers in Japan (EEJ), the institute of Applied Physics of Japan (JSAP), and Japanese Society of Environment and Control in Biology.

Masaki Yamaguchi (Member) was born in Nagoya, Japan, in 1963. He joined the Research Laboratory of Brother Industries, Ltd, in Nagoya, Japan 1987. He received his doctoral degree in Engineering from Shinshu University, Japan in 1994. He is an assistant professor at Tokyo University of Agriculture and Technology since 1995.

His current research interests include development of the welfare apparatus using linear motors and noninvasive medical sensors. His noninvasive approaches include glucose, insulin, and the other hormones

$\mathrm{He}$ is a member of the Institute of Electrical Engineers in Japan (IEEJ), the Japan Diabetes Society, the Japan Society of Medical Electronics and Biological Engineering (JME), and the Magnetics Society of Japan (MSJ). 